\title{
Rearing conditions during the force-feeding period in male mule ducks and their impact upon stress and welfare
}

\author{
Daniel GUÉMENÉa*, Gérard GUY ${ }^{\mathrm{b}}$, Jérôme NOIRAULT ${ }^{\mathrm{a}, \mathrm{b}}$, \\ Nicolas DESTOMBES ${ }^{\mathrm{a}, \mathrm{b}}$, Jean-Michel FAURE ${ }^{\mathrm{a}}$
}

\author{
${ }^{a}$ Unité de Recherches Avicoles, INRA, Centre de Tours-Nouzilly, 37380 Nouzilly, France \\ ${ }^{b}$ Unité Expérimentale des Palmipèdes à Foie Gras d'Artiguères, INRA, Centre de Bordeaux, \\ 1076 route de Haut Mauco, 40280 Benquet, France
}

(Received 1 August 2005 - Accepted 15 May 2006)

\begin{abstract}
The aim of the first experiment conducted was to further characterise HPA axis functionality in male mule ducks during the force-feeding period, by measuring corticosterone levels (Exp. 1). The objectives of the two other experiments were to investigate the impact of different rearing conditions on stress response (Exp. 2) and behaviour patterns (Exp. 3) in male mule ducks. The rearing conditions examined comprised individual (Exps. 1-3) and collective battery cages (Exps. 2, 3), as well as collective floor pens (Exps. 2, 3). The ducks were then fed (Exps. 1-3) by force-feeding for foie gras production or ad libitum (Exp. 1). The highest levels of corticosterone (up to $100 \mathrm{ng} \cdot \mathrm{mL}^{-1}$ ) were measured after initial capture and handling in a large collective rearing pen, transfer to a different environment, initial placement in a net for $10 \mathrm{~min}$ and injection of $5 \mu \mathrm{g} \cdot \mathrm{kg}^{-1} \mathrm{BW}$ of 1-24 ACTH agonist. Both force-fed and non-force fed male mule ducks responded to a first physical constraint in a net by a large increase in corticosterone levels. Their HPA axis was therefore functional although the effect quickly vanished, which was interpreted as an indication that habituation took place. Most often, corticosterone levels measured before and after force-feeding during the force-feeding period did not differ significantly $(P>0.05)$ when the ducks were raised in individual cages, even on the first occurrence. A significant increase in corticosterone levels was observed after the first force-fed meal for both groups of ducks raised collectively, i.e. in cages or floor pens, when the practice involved capture and handling. Following the injection of 0.625 and $5 \mu \mathrm{g} \cdot \mathrm{kg}^{-1} \mathrm{BW}$ doses of $1-24 \mathrm{ACTH}$, cortico-adrenal responses were significantly $(P<0.05)$ higher and lower for ducks raised in collective floor pens compared to those raised in individual cages, respectively. This hypersensitivity and lower maximal capacity may result from a chronic stressful state related to repeated acute stress (i.e. capture and handling twice daily). Ducks raised in cages (individual or collective) spent more time standing (less lying) and less time inactive i.e. expressing passive behaviour patterns, which suggest that they were not presenting signs of passive coping or learned helplessness. Behaviour observations did not provide any indication of stereotyped behaviour. From these results, it could have been concluded that placement in individual battery cages
\end{abstract}

\footnotetext{
*Corresponding author: guemene@ tours.inra.fr
} 
during the limited period of force-feeding are not detrimental in terms of welfare. However, they cannot achieve full wing stretching or express a full range of social behaviours as required by the European Council recommendation (Scientific Committee on Animal Health and Animal Welfare, Welfare aspects of the production of foie gras in ducks and geese, CEC, DGXXIV/B3/AW/R06, 1998, 94 p.). They may also have more difficulty in thermoregulating as indicated by the fact that they had higher frequencies of both panting and watering. In terms of welfare, since signs of acute and possibly chronic stress were observed when the force-feeding procedure involved capture and handling, there is a need to set up new models of collective cages and better define the optimal group size and density to be used in future rearing conditions.

\section{force-feeding / mule ducks / rearing conditions / corticosterone / behaviour}

Résumé - Impacts sur les réponses de stress et le bien-être des conditions d'élevage du canard mulard mâle durant la période de gavage. Dans une première expérience (Exp. 1), la fonctionnalité de l'axe hypothalamus-hypophyse-surrénales (HPA) a été caractérisée durant la période de gavage chez le canard mulard, par mesure de la corticostéronémie (Exp. 1). Les objectifs des autres expériences réalisées étaient d'analyser les effets des conditions d'hébergement sur les réponses de stress (Exp. 2) et les comportements exprimés (Exp. 3). Après avoir été élevés collectivement au sol, les canards ont été transférés en cages batteries individuelles (Exps. 1-3), ou collectives (Exps. 2, 3), ou en loges collectives au sol (Exps. 2, 3). Les canards s'alimentent spontanément ad libitum (Exp. 1) ou reçoivent une alimentation par gavage pour la production de foie gras (Exps. 1-3). Les corticostéronémies les plus élevées (jusqu'à $100 \mathrm{ng} \cdot \mathrm{mL}^{-1}$ plasma) ont été mesurées avant transfert lors d'une première capture, immédiatement après transfert, après une première contention dans un filet pendant 10 minutes et après l'injection de $5 \mu \mathrm{g} \cdot \mathrm{kg}^{-1} \mathrm{PV}$ de $1-24$ ACTH. Les canards, gavés ou non, ont répondu par une élévation significative de leur corticostéronémie après une première contention dans un filet pendant 10 minutes. La réponse s'est progressivement estompée en dépit du fait que l'axe HPA était fonctionnel ; résultats qui suggèrent la mise en place d'un processus d'habituation. Au cours de la période expérimentale, l'acte de gavage n'induit généralement pas d'élévation $(P>0,05)$ de la corticostéronémie, chez les canards placés en cage individuelle. Ce résultat suggère que l'acte de gavage n'est pas perçu comme un stress aigu majeur par le canard mulard dans ces conditions expérimentales. Une augmentation significative de la corticostéronémie a été observée après le premier repas de gavage pour les canards des deux groupes élevés collectivement (c.a.d. cage et loge au sol); conditions dans lesquelles la pratique de l'acte nécessite une capture et une contention. Les réponses en corticostérone mesurées après injection i.m. de doses de 0,625 ou $5 \mu \mathrm{g} \cdot \mathrm{kg}^{-1} \mathrm{PV}$ de 1-24 ACTH, pour ces mêmes groupes de canards, suggèrent un état d'hypersensibilité et une diminution de la capacité de réponse maximale des surrénales, qui caractérisent potentiellement un état de stress chronique. Cet état de fait a pu être engendré par la répétition de stress aigus liés à l'acte de gavage dans ces conditions expérimentales impliquant pour la pratique de l'acte gavage : capture, manipulation et contention deux fois par jour. Les observations comportementales n'ont pas permis de mettre en évidence de comportements stéréotypés chez le canard mulard. Les canards placés en cages batteries ont passé plus de temps debout et sont plus actifs ; résultat qui suggèrent qu'ils n'expriment pas de signes d'adaptation passive ou de passivité acquise. Nous pourrions donc en conclure que le placement en cage individuelle durant la période de gavage n'a pas de conséquence négative en termes de bien-être. Les canards ne peuvent toutefois dans ces conditions expérimentales réaliser l'étirement complet des ailes ainsi que divers comportements sociaux qui sont stipulés dans la recommandation du Conseil de l'Europe (Scientific Committee on Animal Health and Animal Welfare, Welfare aspects of the production of foie gras in ducks and geese, CEC, DGXXIV/B3/AW/R06, 1998, 94 p.). En outre, ils ont sans doute des besoins supérieurs en termes de thermorégulation, comme le suggère l'observation de fréquences supérieures d'halètement et d'abreuvement. Des signes de stress aigu et éventuellement chronique ayant été mis en évidence lorsque la pratique du gavage exige une capture et une contention, il est nécessaire de concevoir de nouveaux modèles de cage collective et aussi de mieux définir les tailles de groupe et les densités optimales à utiliser dans ces conditions d'hébergement.

gavage / canard mulard / corticostérone / comportement / hébergement 


\section{INTRODUCTION}

Production of "Foie-gras" involves force-feeding twice daily over at least a 12-day period and it has been hypothesised that such treatment may be perceived as stressful and consequently the cause of hypothalamus-pituitary-adrenal

(HPA)

axis stimulation. Indeed, manipulation such as catching and handling has been shown to induce stress responses, reflected by rises in corticosterone levels in chickens [19,24], quails [28], turkeys [14] and ducks [27]. However, the results from a previously published study [13] showed that force-feeding per se does not induce any consistent increase in corticosterone levels and did not provide any indication that it leads to a chronic stress state, whereas the adrenal glands are fully responsive to ACTH challenge. This absence of corticosterone response to force-feeding might be due either to desensitisation of the HPA-axis at a more central level or to the fact that force-feeding is not really perceived as stressful. In order to check these hypotheses, it would be valuable to know whether such ducks are able to perceive and to react to a supposedly stressful physical treatment during the force-feeding period. This would provide a good indication that the HPA-axis is functional and that the ducks do not perceive force-feeding as a source of acute stress or express it differently.

Although, the placing of ducks in battery cages during the force-feeding process is the most common production practice, it is considered to be more detrimental in terms of welfare, mainly because of the restricted space available [2]. Likewise, it has been shown that individual cages represent a stressful environment for laying hens $[1,8,26]$ and that poor environments cause chronic stress $[3,16]$. However, the results of a previous study indicated that, when mule ducks are placed in individual cages, force-feeding does not appear to lead to an increase in corticosterone, nor to a sensitisation or an exhaustion of the HPA axis, which would have been an indication of acute and chronic stress states, respectively [13]. However, when birds are raised in collective cages or floor pens, force-feeding requires capture and handling twice a day and repeated handling, an overall procedure that can possibly lead to a chronic stress state. Since the individual cage will be banned in the context of the adopted recommendation [2], we investigated whether placing male mule ducks in collective rearing conditions during the force-feeding period, would lead to different results in terms of acute and chronic stress, and expressed behaviour. The approach to investigating acute stress consisted of measuring changes in corticosterone levels on different days throughout the force-feeding period [13]. Investigation of chronic stress comprised ACTH stimulation [30] and measuring adreno-corticotropic axis sensitivity and reactivity $[16,20,21,25]$. Various behaviour patterns and postures were recorded throughout for ducks in different rearing environments. Two types of reaction can be observed when animals are placed in frustrating situations: passive coping or learned helplessness and stereotyped behaviour, the most common form of the last type being stereotyped preening $[5,6,23,32]$. The prediction was that ducks kept in individual cages would show behaviours that are more passive and/or more preening behaviour than birds kept in collective pens. It could also be predicted that if the problems are due to space and social restriction the major differences should be between individual and collective cages.

The present experiments were thus undertaken in continuation of previous studies $[13,27]$ to first investigate further HPAaxis functionality in male mule ducks and having this information in hand, to check for the possible interactions between 
force-feeding practice and rearing environment on behavioural and physiological indicators of stress and poor welfare.

\section{MATERIALS AND METHODS}

\subsection{Experimental animals and general rearing conditions}

Three independent experiments were conducted for the present study. HPA axis' functionality and stress responses were investigated by measuring corticosterone plasma levels in experiments 1 and 2, while behaviour patterns were studied in experiment 3. All the animals were kept within the limits of what is done in practical conditions for foie gras production. Male mule ducks hatched from crossbreeding between male muscovy ducks (Cairina moschata) and female Pekin ducks (Anas platyrhynchos) were raised in a collective floor pen. They were reared in straw-bedded floor pens $(6 \times 2 \mathrm{~m})$ until 6 weeks of age and on slatted floors thereafter until the beginning of the force-feeding period. After 6 weeks of age, the ducks also had access to a winter garden $(2 \times 3 \mathrm{~m})$ located next to each pen. Continuous light was provided during the first 4 days and the photoperiod was $14 \mathrm{~h}$ thereafter. Infrared brooders provided heat according to duck requirements during the first 6 weeks, and food was available ad libitum (2700 kcal, $18 \%$ protein). From 6 to 11 weeks of age, the ducks were food restricted (Exps. 1, 2) or $250 \mathrm{~g} \cdot \mathrm{day}^{-1} \cdot \mathrm{duck}^{-1}$ (Exp. 3), respectively to approximately $80 \%$ of ad libitum consumption. In experiment 3 , the amount was further limited to $220 \mathrm{~g} \cdot \mathrm{duck}^{-1} \cdot \mathrm{day}^{-1}$ between 11 and 13 weeks of age. In order to prepare ducks for the force-feeding period, the amount of food provided daily was increased thereafter by $20 \mathrm{~g} \cdot \mathrm{day}^{-1}$ in order to reach $380 \mathrm{~g} \cdot \mathrm{duck}^{-1} \cdot \mathrm{day}^{-1}$ just before the beginning of the force-feeding period. This treatment which consisted in a food restriction period followed by a progressive in- crease in the amount of available food is the most common process to prepare mule ducks for force-feeding. It is intended to expand the lower part of the oesophagus, since there is no crop in ducks, in order to increase the ingestion capacity.

On the morning of the first day (day 1 of force-feeding), ducks were transferred from the collective floor pens to individual battery cages (Exps. 1-3; $\mathrm{L}=54, \mathrm{w}=20$, $\mathrm{h}=31 \mathrm{~cm})$, collective cages $(85 \times 85 \mathrm{~cm}$; 4 and 5 ducks per cage for Exps. 2, 3, respectively) or slatted collective floor pens $(300 \times 100 \mathrm{~cm} ; 12$ and 13 ducks per pen for experiments 2 and 3, respectively). Individual cages were designed with an opening allowing the duck to move its head and neck freely outside the cage. During the 12.5 or 13.5 day force-feeding period, the ducks received 25 (Exps. 1, 2), or 27 meals (Exp. 3), i.e. two meals per day at 12 hour intervals (from $07.00 \mathrm{~h}$ to $08.00 \mathrm{~h}$ and from $19.00 \mathrm{~h}$ to $20.00 \mathrm{~h}$ for all ducks). Forcefed ducks were fed with corn mash $(53 \%$ Maïsadour pellets mixed with $47 \%$ water; Exp. 2) or moderately cooked corn with added salt and fat (Exps. 1, 3 [Groups FF]). The total amounts of food ingested per duck during the experimental period were $9.4 \mathrm{~kg}$ (Exp. 1), $9.2 \mathrm{~kg}$ (Exp. 2) and $10.5,10.4$ and $11.5 \mathrm{~kg}$ for the ducks raised in individual cages, collective cages and floor pens (Exp. 3), respectively. The nonforce-fed ducks included in experiment 1 (Groups NF, $\mathrm{n}=30$ ) were fed $100 \mathrm{~g}$ per meal of the commercial diet distributed previously twice daily. Initial (Day 1) and final body weights (Day 13) were recorded, as well as liver weights (D13) after slaughtering of force-fed ducks in experiments 1 and 2 .

\subsection{Sampling procedure and corticosterone radioimmunoassay}

Blood samples were withdrawn, from the same birds throughout for a specific experiment, during experiments 1 and 2 
( $\mathrm{n}=12$ birds for experiment 1 and 14 for Exp. 2) by occipital sinus puncture, according to Vuillaume and Tournut [31]. This method was shown to be the fastest to be realised (less than $30 \mathrm{~s}$ per bleeding) and the one giving the lowest basal levels [27]. Two blood samples were withdrawn before initiation of the force-feeding treatment. The first, 5 (Exp. 1) or 2 (Exp. 2) days before onset of the force-feeding period (D-5 or D-2) while the ducks were still in the collective floor pens and the second at the time of transfer, before placing the ducks in their final force-feeding environment. During the force-feeding or experimental period, blood samples were withdrawn before and after the first, second, third, fourteenth and twenty-fourth experimental meals on the evening of day 1 , morning and evening of day 2 and mornings of days 8 and 13, respectively. The two last sets of samples were collected before and after the first and second occasional treatments in experiment 1 (Treatments NF2 (non force-fed) and FF2 (force fed)). Consecutive samples were withdrawn at 105 (Exp. 1) or 90 minute intervals (Exp. 2), the first being collected $75 \mathrm{~min}$ before feeding, in order to obtain a measurement of the basal level and the second 30 (Exp. 1) or $15 \mathrm{~min}$ utes (Exp. 2) after force-feeding. When applied (Exp. 1), the 10 min stressful treatment took place 5 min after the meal and ended $15 \mathrm{~min}$ before collection of the second blood sample. On day 11 (Exp. 2) a Thorn test was performed [30] consisting of collection of blood samples immediately prior to and $15 \mathrm{~min}$ after injection of a 1-24 ACTH agonist at two different doses $\left(0.625\right.$ and $5 \mu \mathrm{g} \cdot \mathrm{kg}^{-1} \mathrm{BW}$, Immediate Synacthen, Novartis, 2, 4 rue Lionel Terray, BP 308, 92506 Rueil Malmaison Cedex, France, $1 \mathrm{mg}=100$ I.U.). Injectionsampling intervals, ACTH agonist doses and puncture sites were selected according to the results of previous studies [13, 27]. Blood samples were collected in heparinised vacutainers and centrifuged. The plasma was then separated and stored at $-20{ }^{\circ} \mathrm{C}$ before corticosterone assay. Plasma corticosterone levels were estimated in duplicate using a specific radioimmunoassay [7].

\subsection{Specific experimental procedures}

\subsubsection{Experiment 1}

Sixty randomly selected male mule ducks from a medium weight genotype were transferred at 12 weeks of age to individual cages for the final experimental period. Half of these ducks were force-fed twice daily thereafter (Group FF, $\mathrm{n}=30$ ) and the other half were kept as non-forcefed controls (Group NF, $\mathrm{n}=30$ ).

Each of these two groups was subdivided into 3 sub-groups $(\mathrm{n}=10)$ which were assigned to different treatments. In treatment 1 (NF1 and FF1; "controls"), the ducks were not submitted to any further specific treatment. In treatment 2 (NF2 and FF2: "occasional net"), the ducks were placed on the floor tightly constrained in a net for a period of $10 \mathrm{~min}$ after the 14th and 24th force feeding meals (8th and 13th day). This treatment was initiated 5 min after being force-fed. Under treatment 3 (NF3 and FF3: "systematic net"), the procedure was similar to treatment 2 but the treatment was applied twice daily throughout the experimental period.

\subsubsection{Experiment 2}

In the morning of the first day of the trial, 72 male mule ducks from a medium weight genotype, 12 weeks old, were randomly assigned to one of three rearing environments $(\mathrm{n}=24 \times 3)$. In the first group ducks were housed in two collective slatted floor pens $(n=12 \times 2)$, in the second ducks were housed in six collective cages $(n=4 \times 6)$ and in the last group ducks were housed in individual cages $(n=24)$. 


\subsubsection{Experiment 3}

At 14 weeks of age, 71 out of 120 male mule ducks from a heavy weight genotype were selected from the central classes of the body weight histogram and were randomly assigned to one of the three rearing environments. In the first group, the ducks were housed in two collective slatted floor pens $(n=13 \times 2)$, in the second ducks were housed in six collective cages $(n=5 \times 6)$ and in the last experimental group 20 ducks were housed in individual cages, all placed in the same building.

Behaviour observations were performed throughout the force-feeding period. Each treatment was video-recorded for two hours per day, one in the morning and one in the afternoon. The order in which the 3 treatments were video-recorded was randomised. The two floor pens were video-recorded on alternate days, whereas each collective cage and each group of 4 contiguous individual cages were videorecorded every 5 days. Videotapes were then observed by scan-sampling techniques. The individual behaviour patterns and postures were observed every minute. All the ducks could be seen and observed all the time in the collective and individual cages, whereas in the floor pens some ducks were not visible from time to time. They could either be hidden behind another duck or in a limited blind area that was technically not possible to include in the field of the camera. Two postures were observed from these sets of records: i.e. standing and lying. Eight behaviour patterns were quantified. The first was panting, a behaviour pattern whose expression is related to heat regulation. Their beaks are then wide open and their throats flutter rapidly in order to increase the ventilation rate for calorie releasing. This behaviour pattern can be performed at the same time as some of the other patterns observed. However, these other patterns were mutu- ally exclusive. Panting was consequently analysed independently.

The other seven behaviour patterns observed were the followings: drinking (duck placing its beak in the water trough), sleeping (duck remains immobile with its beak in close contact with the feathers of either the chest or the back), preening (beak in contact with feathers and moves laterally to keep the feathers in good condition), stretching (duck stretches one or both wings), shaking (duck shakes its body, i.e. rotates its body around its longitudinal axis), wagging (duck makes lateral movements of the tail and all other behaviours). This last category mostly if not exclusively includes passive behaviour, i.e. that the duck is inactive while standing or lying still. At each scan a bird was thus standing or lying, panting or not and performing one of the 7 behaviour patterns. Any of the $2 \times 2 \times 7$ combinations might be theoretically possible although some were never observed. In some analyses, behaviours related to comfort movements (preening, stretching, shaking and wagging) were grouped together.

\subsection{Statistical analysis}

Corticosterone data were compared by analysis of variance (ANOVA) and the Fisher protected least significant difference (PLSD) post hoc test when appropriate $(P<0.05$, ANOVA $)$. All corticosterone values are expressed as means \pm standard error of the mean and the level of significance is $P<0.05$ unless otherwise stated. The ducks kept in collective cages or pens were considered as independent.

The ideal for our behavioural data would have been to perform a three-factor analysis including 13 days (during the force-feeding period), 2 hours (time of the day: morning-afternoon) and 3 treatments (rearing conditions). This was, however, impossible since only one measurement 
was available for each elementary treatment (birds could not be individually identified in collective cages or pens). The 3 factors, i.e. time (morning or afternoon), day of force-feeding (1 to 13) and rearing conditions (collective pen, collective cage and individual cage), were therefore analysed independently. On day one of the force-feeding period, only the afternoon meal was provided and no observation was performed after this first forcefeeding. Videotapes from the following 13 days of the force-feeding period were analysed. The number of tests was also relatively high ( 1 and 7 behaviour patterns, and 2 postures). Such an experimental design increases the risk of first order and therefore to alleviate this, a difference was only considered as significant if $P<0.001$, or as a tendency if $0.001<P<0.01$ and non-significant if $P>0.01$. Statistical analyses were carried out using Statview (Abacus Concept Inc. Berkeley, CV, USA) and SYSTAT (SYSTAT Inc. USA) programmes for Apple MacIntosh.

\section{RESULTS}

\subsection{Experiment 1}

Initial live body weights ranged between $4.2 \pm 0.3$ and $4.4 \pm 0.4 \mathrm{~kg}$ and were comparable for all groups $(P>0.05)$. By the end of the experimental period, body weights differed according to whether the ducks were submitted to force-feeding or not. Body weights did not otherwise differ significantly between treatments or within groups and ranged between $4.1 \pm 0.5$ and $4.5 \pm 0.5 \mathrm{~kg}$ and, $6.9 \pm 0.3$ and $7.3 \pm 0.6 \mathrm{~kg}$ for groups NF and FF, respectively. The average liver weights measured for the different sub-groups of group FF were comparable $(P=0.78)$ and ranged between $613 \pm 143 \mathrm{~g}$ and $685 \pm 194 \mathrm{~g}$.

High levels of corticosterone (up to $100 \mathrm{ng} \cdot \mathrm{mL}^{-1}$ ) were measured while the ducks were still kept in the large collective floor pen and after transfer to individual battery cages (Fig. 1). When treatments were taken into consideration individually, the post force-feeding level was significantly higher $(P<0.05)$ compared to the initial level for group FF1 on day 1 (Fig. 1). No such significant increase was observed for group NF1 or FF2, this last group being submitted to exactly the same treatment than FF1 at the time of the experimental period (Fig. 1). A significant increase was, however, also observed for group NF2 in the absence of any specific treatment (Fig. 1). Initial tight constraint induced a significant increase in corticosterone $(P<0.05)$ with significantly higher levels $(P<0.05)$ than those of the corresponding force-fed (FF: 1,2) and non-force-fed treatments (NF: 1, 2). The responses of the force-fed ducks (Group FF3) after being kept in a net for the first time was significantly higher $(P<$ $0.05)$ than that of the corresponding nonforce-fed ducks (Group NF3) submitted to the same physical treatment. The response to this constraint treatment gradually decreased on subsequent days, although the difference remained significant $(P<0.05)$ until the third test for treatment NF3. On days 8 and 13, corticosterone levels remained stable for the ducks receiving treatments 1 and 3 in both group NF and group FF.

On day 8, the first occasional tight constraint applied to ducks receiving treatments NF2 and FF2 resulted in significant increases $(P<0.05)$ in corticosterone levels (Fig. 1). On day 13, the second occasional stress also resulted in increased corticosterone levels but the difference only reached significance for the non-force-fed ducks (NF2) (Fig. 1).

\subsection{Experiment 2}

Initial and final live body weights ranged between $4.0 \pm 0.3$ and $4.1 \pm 0.4 \mathrm{~kg}$ 


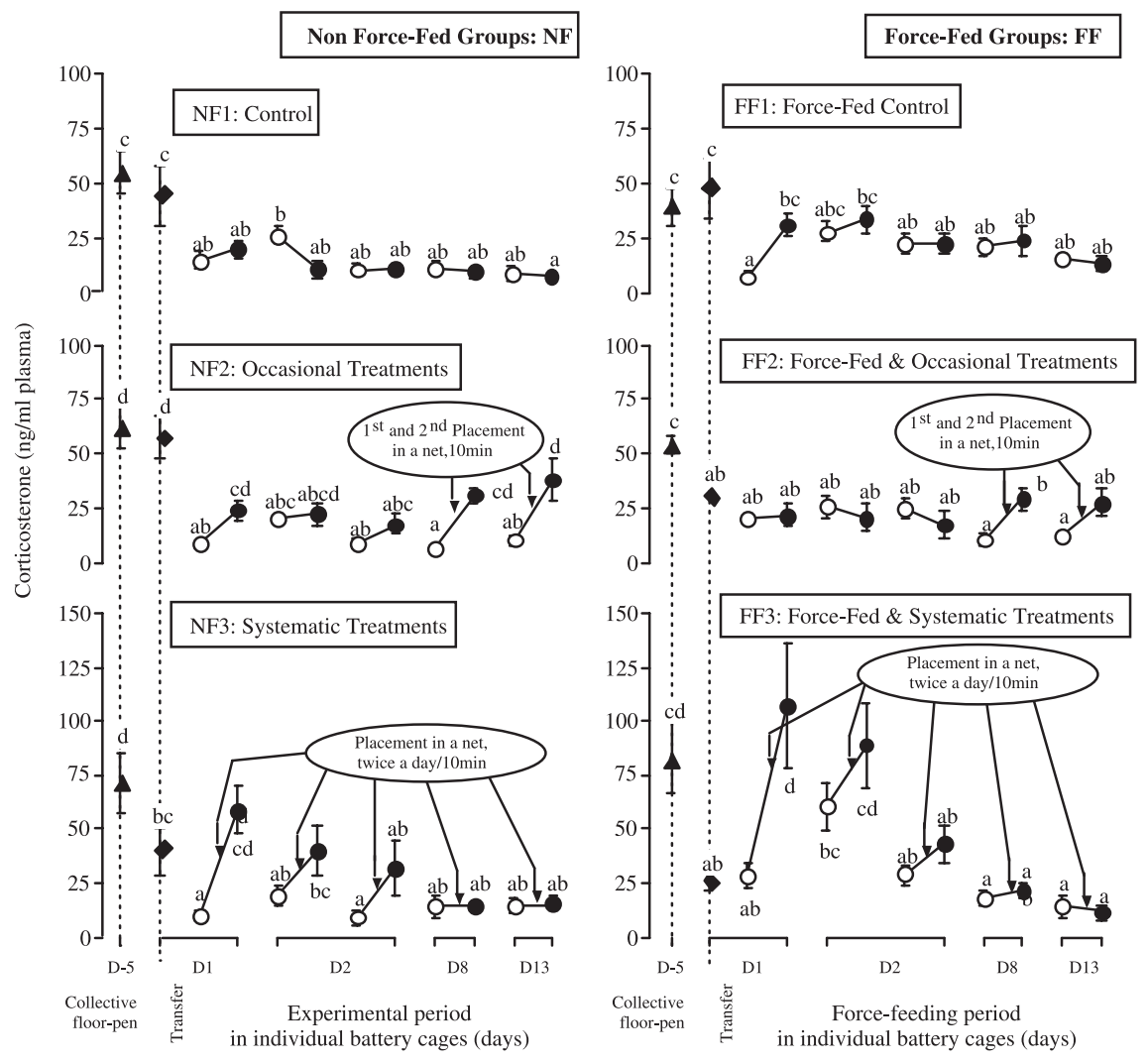

Figure 1. Changes in corticosterone concentrations (ng. $\mathrm{mL}^{-1}$ plasma) in male mule ducks during the pre-experimental period (pre-force-feeding regime) ( $\mathbf{\Lambda}$, floor pen), at the time of transfer to individual battery cages $(\downarrow)$, during the experimental period [before $(\mathrm{O})$ and $10 \mathrm{~min}$ after forcefeeding $(\bullet)$ [Groups FF] or at the corresponding timetable [Groups NF]]. (Mean \pm SEM). a, b, . . : means for a specific group with different letters differ significantly $(P<0.05)$.

and $6.0 \pm 0.5$ and $6.1 \pm 0.4 \mathrm{~kg}$ and were comparable $(P>0.05)$ for all groups. Liver weights averaged $541 \mathrm{~g}$ and were comparable for the three experimental groups.

High levels of corticosterone were measured before the beginning of the trial (D-2) and during transfer (D0) (Fig. 2). Corticosterone levels measured before and after force-feeding for the group reared in individual cages were comparable throughout. A significant increase in corticosterone levels were observed after the first force-fed meal for both groups of ducks raised collectively, i.e. in collective cages or floor pens. Levels measured before and after forcefeeding were comparable thereafter. Corticosterone levels measured after ACTH injection at a dose of $0.625 \mu \mathrm{g} \cdot \mathrm{kg}^{-1} \mathrm{BW}$ were significantly higher for the ducks raised in collective floor pens. After injection at a dose of $5 \mu \mathrm{g} \cdot \mathrm{kg}^{-1} \mathrm{BW}$, corticosterone levels of the group raised in individual cages were significantly higher $(P<0.05)$ than those of the groups raised collectively (Fig. 2). Levels after injection of the two different doses were comparable for ducks 


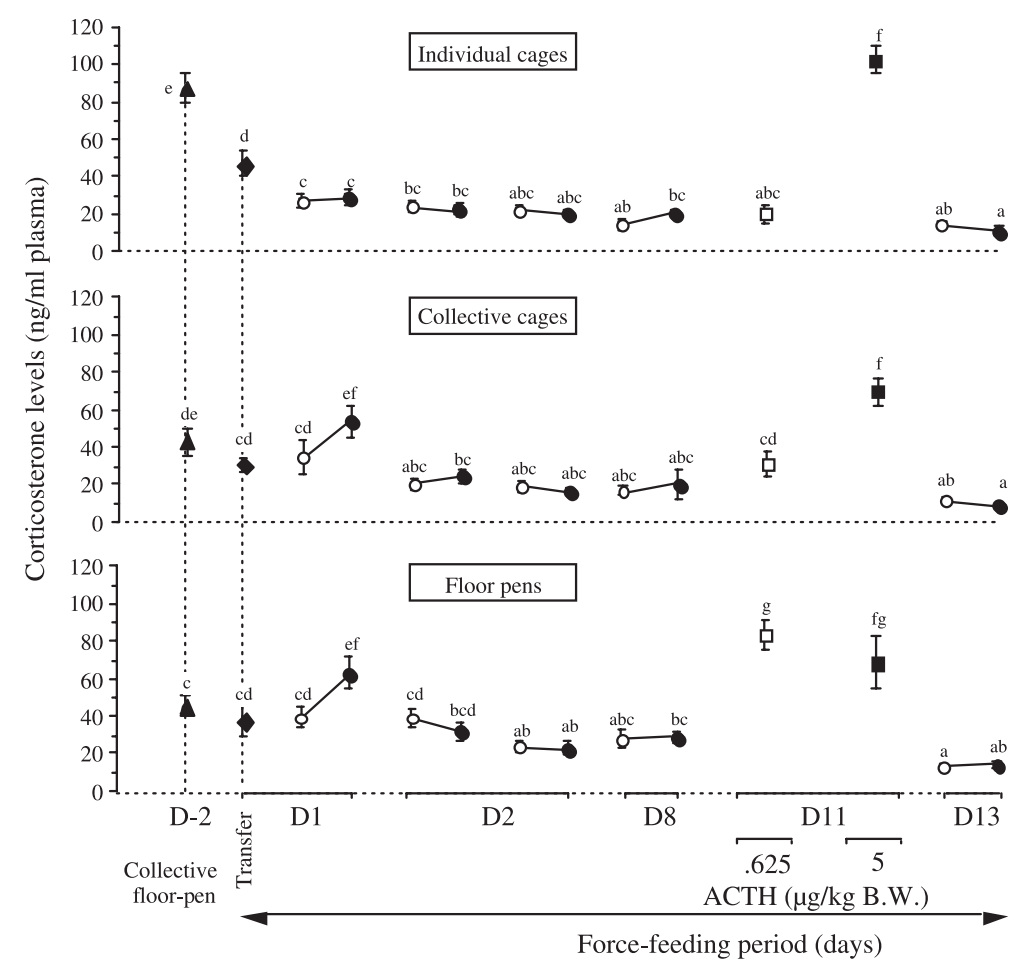

Figure 2. Changes in corticosterone levels (ng. $\mathrm{mL}^{-1}$ plasma) during the pre-force-feeding period $(\boldsymbol{\Delta})$, at the time of transfer $(\diamond)$, during the force-feeding period $[75 \mathrm{~min}$ before $(\mathrm{O})$ and $15 \mathrm{~min}$ after force-feeding $(\bullet)$ or $15 \mathrm{~min}$ after injection of ACTH at doses of 0.625 (口) or $\left.5 \mu \mathrm{g}^{\mathrm{k}} \mathrm{kg}^{-1} \mathrm{BW}(\boldsymbol{\square})\right]$ in male mule ducks raised in individual battery cages, collective cages or floor pens after transfer. (Mean \pm SEM). a,b, ..., g: means for a specific group with different letters differ significantly $(P<0.05)$.

raised in collective floor pens, whereas they were significantly higher with the highest dose for both groups of ducks raised in cages.

\subsection{Experiment 3}

The results of all statistical analyses are reported in Table I. The results regarding the proportions of time spent performing the different behaviour patterns (a), the proportions of time spent panting or not (b) and the proportions of time spent lying or standing (c), during the 13 days of the force-feeding period, in the morning and in the afternoon and in the different rearing environments [individual cages, collective cages or floor pens] are presented in Figures 3 to 5 , respectively.

The frequency of panting was significantly affected by the day, with a progressive increase throughout (Fig. 3b). It tended to differ depending on the rearing conditions (Tab. I), with higher frequencies for ducks raised in individual cages (Fig. 5b), but was not affected by the time of day (morning vs. afternoon) (Fig. 4b).

Postures were not affected by the day or by the time of day (Tab. I, Figs. 3c and 
Table I. Results of the one factor analysis of variance of the behavioural data.

\begin{tabular}{lccccccccc}
\hline & Standing & Panting & Drinking & Sleeping & Preening & Stretching & Wagging & Shaking & Other \\
\hline Hour & NS & NS & $* * *$ & NS & $* * *$ & $* *$ & NS & NS & NS \\
Day & NS & $* * *$ & NS & NS & NS & NS & NS & NS & NS \\
Rearing & $* * *$ & $* *$ & $* * *$ & NS & NS & NS & NS & NS & $* * *$ \\
\hline
\end{tabular}

***: $P<0.001 ; * *: P<0.01 ; *: P<0.05$; NS: $P>0.05$.
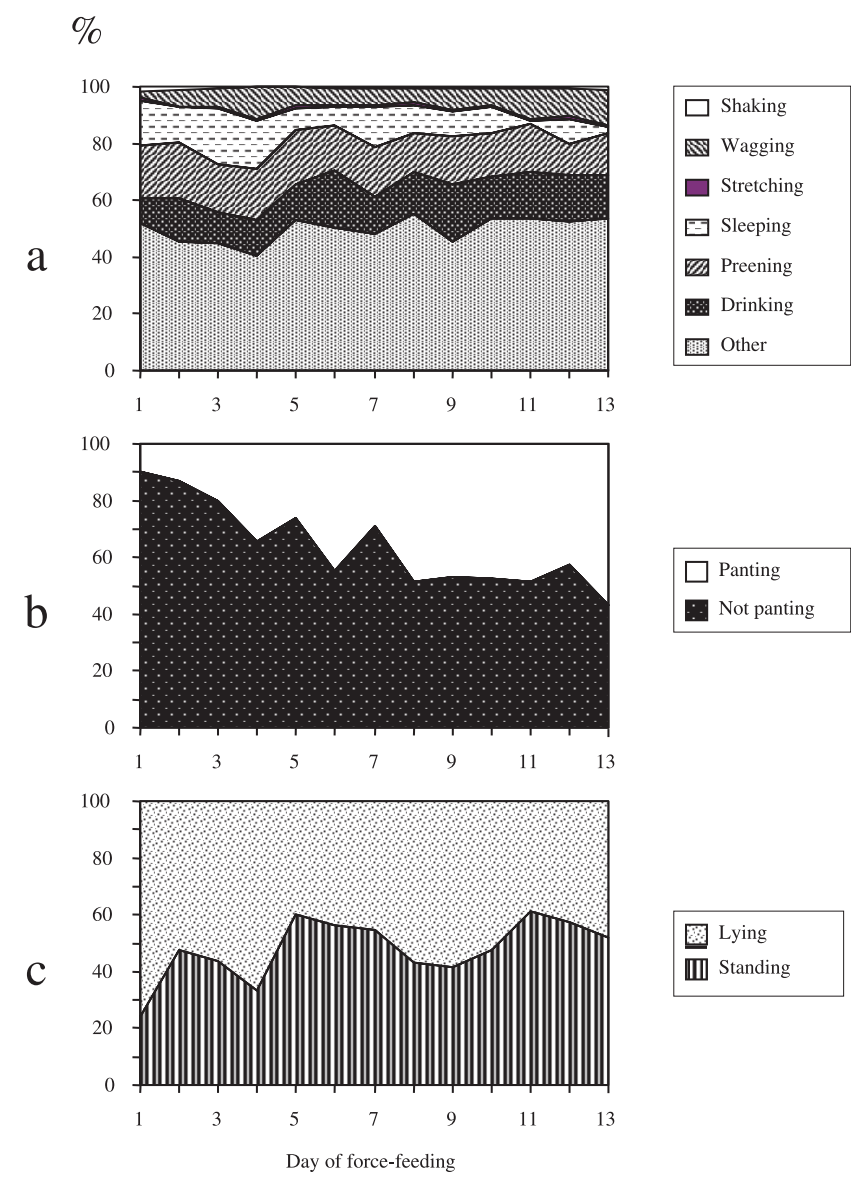

Figure 3. Changes during the 13 days of the force-feeding period in the proportions of time (\%) spent: (a) performing different behaviour patterns; (b) panting or not; (c) lying or standing. 


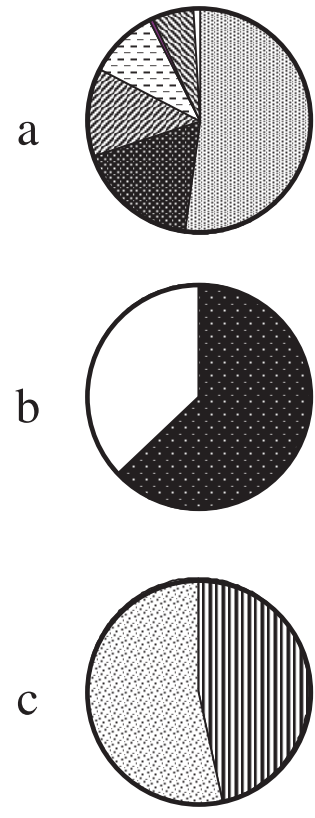

AM
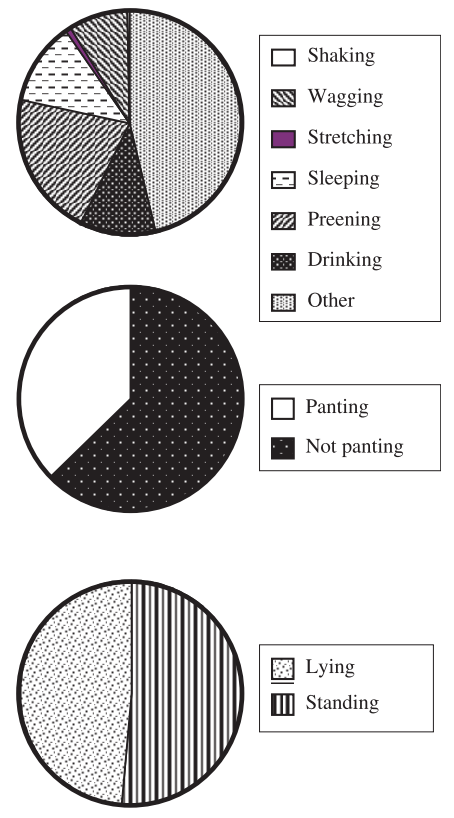

PM

Figure 4. Proportions of time (\%) spent in the morning (AM) and in the afternoon (PM): (a) performing different behaviour patterns; (b) panting or not; (c) lying or standing.

4c) but the ducks spent more time standing in individual $(55 \%)$ and collective cages (53\%) than on floor pens (39\%) (Fig. 5c).

The frequency of behaviour patterns was not affected by the day (Tab. I and Fig. 3a). Drinking was affected by the time of day and by rearing conditions. Ducks spent more time drinking in the morning (Fig. 4a) than in the afternoon (17.8 vs. $11.1 \%)$ and more time drinking in individual cages than in collective cages or floor pens $(24.3,10.8$, and $10.3 \%$, respectively) (Fig. 5a). Preening was affected by time of day, with ducks spending more time preening in the afternoon $(13.4 \%)$ than in the morning (7.8\%) (Fig. 4a). They also tended to spend more time stretching in the afternoon (5.9\% vs. $3.1 \%$ ). The frequency of the category of "other" behaviour patterns was significantly affected by the rearing conditions and was much more frequently expressed in floor pens than in collective or individual cages (62.5 vs. 49.3 and 31.8, respectively).

\section{DISCUSSION}

Altogether, the above results extend and confirm those from previous studies [9, $13,27]$. Indeed, when placed in individual cages the majority of male mule ducks never responded by an increase in corticosterone levels after force-feeding, even on its first occurrence (Present results: Exps. 1, 2; [13]). Force-fed and non-forcefed male mule ducks were, however, sensitive to physical treatments such as a tight constraint, as indicated by the considerable changes measured in corticosterone levels. Under the latter conditions, corticosterone levels were as high as when handled for the 


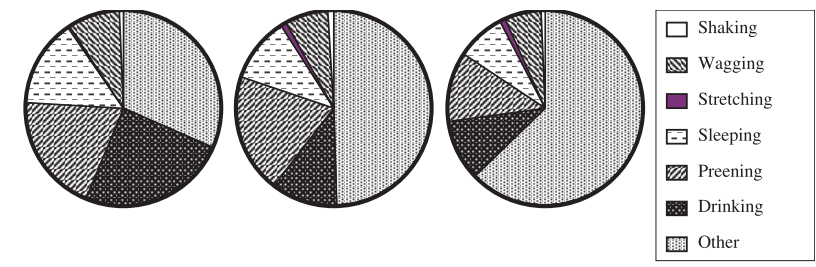

b
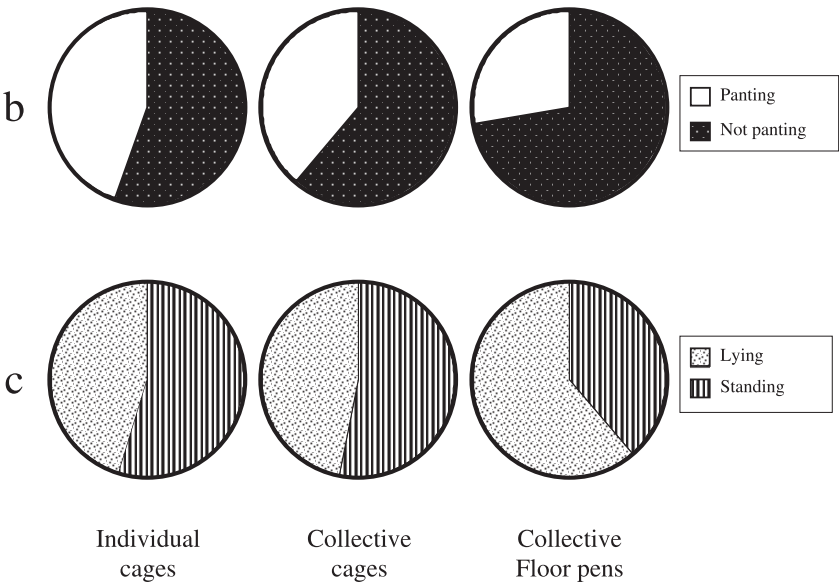

Figure 5. Proportions of time (\%) spent in individual cages, in collective cages and in floor pens: (a) performing different behaviour patterns; (b) panting or not; (c) lying or standing.

first time after capture in the collective pen and at the time of transfer. Whenever an increase in corticosterone level was observed after force-feeding (Day 1, Group FF1, Exp. 1), the increase was of much lower amplitude than following placement in a net. It is noticeable that response to physical treatments progressively vanished with time, and this is an indication of habituation. Although contradictory results have previously been reported regarding the establishment of such a process [22], it has also been previously observed following routine handling in different species $[3,11$, $12,17]$. Consequently, we cannot exclude the possibility that repeated physical manipulations may have limited the potential effectiveness of force feeding per se to trigger increased corticosterone levels since it appears that they became accustomed quickly. However, tight constraints applied at the same time resulted in such a response and therefore a process of habituation cannot explain the absence of physiological effects after the first experience of forcefeeding. It should, however, be pointed out that on D1, the much higher corticosterone levels observed in FF3 compared to NF3 might be due to a potentialisation of the stress response by the force-feeding. Under such a hypothesis, we cannot exclude that the treatment, consisting in force-feeding plus constraint in a net, is more stressful that the latest component alone. We can, however, state that during the force feeding period, the HPA axis of male mule ducks is fully functional and that the absence of response or its limited amplitude is due to the fact that the force-feeding procedure itself is not a source of acute stress or a very mild one.

On the contrary, an increase in corticosterone levels was observed following the first force-feeding procedure when ducks 
were raised collectively (Exp. 2). We cannot exclude that these increases of limited amplitude were incidental. However, an hypersensitivity of the adrenal glands and a decrease in their maximal reactivity were observed by the end of the experiment for ducks raised in collective floor pens during the force-feeding period, as reflected by higher and lower corticosterone responses after challenge with low and high doses of ACTH, respectively. It has previously been established that repeated acute stress can induce such hypersensitivity of the adrenal glands $[4,15,16]$. Therefore, altogether, these results suggest that when raised collectively, the capture and immobilisation, which are necessary to proceed to force feeding, can be a source of repeated acute stress that can lead to a chronic stressful state. On the contrary, it has been established that chronic stress causes a decrease in productivity [3]. The lack of difference between live body weights and liver weights in the different raising environments shows that productivity was not affected by the rearing environment during the force-feeding period. This discrepancy can probably be explained by the absence of major chronic stress or by the fact that forced ingestion of large amounts of food may have impaired a possible negative effect.

A progressive increase in the expression of panting behaviour as fattening progresses could possibly indicate a welfare problem. This increase might be due either to a change in this behaviour pattern directly related to force-feeding or to an increase in the ambient temperature during the experimental period, which took place in May. Although we cannot exclude that differences occurred at the level of the ducks, analysis of the inside temperature throughout did not show any significant increase $(P>0.80)$, Panting observed in the present study was thus probably associated with a thermoregulatory process occurring in response to changes in metabolism dur- ing the force-feeding period. It can be hypothesised that it is because ducks cannot fully spread their wings. Furthermore, although the temperatures inside the room were comparable, it might have not been the same at the duck level. Indeed, the plain surface represented approximately $12 \%$ in the collective cage compared to $22 \%$ in the individual cage, which probably modified airflow throughout the cage. However, although we did not check, such a higher surface of plain floor should improve foot condition and subsequently welfare. However, since the birds can move freely in collective cages, it is necessary to reduce the plain floor surface as much as possible in order to insure optimal drainage of the manure.

The greater frequency of drinking patterns observed in the individual cage might be related to the same physiological mechanisms as panting. It was not technically possible to measure water consumption and this behaviour pattern was not observed in enough details to distinguish between water drinking or spreading. It is not to exclude that real drinking was more important in individual cages since water loss through panting should have been higher for ducks placed in individual cages. It is also likely that at least part of the drinking observed corresponded in fact to water spreading on the feathers, rather than drinking. However, this behaviour pattern might also have played a thermoregulatory role.

Positive or negative social interactions were incidentally observed but, being short events, it was not possible to quantify them by the scan sampling method and our video records were not appropriate to do so. Thus, the category "other activities" mostly relates to inactivity while the duck is standing or lying, i.e. passive behaviour. The fact that ducks placed in individual cages spend more time being active could indicate that they show no sign of passive coping or learned helplessness, 
a type of response often observed when animals are placed in a poor environment [10]. The longer time spent standing by these same birds could be interpreted either similarly or as the consequence of an uncomfortable floor preventing more lying. However, individual cage floor had more plain surface than the collective ones and was covered with plastic instead of wire mesh. Moreover, the second hypothesis is rather incompatible with the observed tendency to spend more time sleeping in individual cages. Stereotypes are also frequently associated with bad welfare conditions (restricted space and/or poor environment) and at least in birds are often expressed by an increase in the frequency of the preening behaviour [5]. Preening itself and the behaviour patterns that are associated with preening such as stretching, body shaking and tail wagging are generally more frequent in stressful conditions [18]. In the present study, these behaviour patterns are, however, unaffected by the rearing conditions.

\section{CONCLUSION}

Data from the present experiments indicate that force-fed male mule ducks are able to perceive external stimuli as stressful and to react to such sources of stress by an increase in their corticosterone levels. Thus the HPA axis is fully functional and these results support the previous hypothesis that forcefeeding is not or is only a limited source of acute stress when ducks are raised in individual battery cages. Moreover, behaviour observations did not provide evidence of passive coping, learned helplessness or stereotyped behaviour when the ducks were placed in such conditions during the force-feeding period. However, male mule ducks placed in individual cages cannot achieve full wing stretching or, although they were not quantified, express a full range of social behaviours as required by the European Council recommendation [29]. Furthermore, they may also have more thermoregulatory difficulties, under this rearing condition, as indicated by the observed higher frequencies of panting and interactions with the water. However, signs of acute and possibly chronic stress were observed when the force-feeding procedure involved capture and handling, i.e. when ducks were placed in collective cages or floor pens. In terms of welfare, there is thus a need to better define the optimal characteristics of the collective cage conditions to be used, both in terms of equipment, as well as group size and density, in order to minimise the possible detrimental impacts of collective rearing.

\section{ACKNOWLEDGEMENTS}

We thank Dr. R.J. Etches (Origen Therapeutics, CA 94010, USA) for supplying the materials used in the corticosterone assays. The authors also thank all the people who contributed to this study and especially Maryse Garreau-Mills, Monique Marché and Pascal Gouraud for expert technical assistance, Evelyne Sazy and Luc Mirabito for their contribution to finding part of the financial support and Doreen Raine for greatly improving the grammatical quality of the manuscript. This work was supported by grants from the Ministère de l'Éducation Nationale, de la Recherche et de la Technologie and the Ministère de l'Agriculture et de la Pêche [Institut National de la Recherche Agronomique, Direction Générale de l'Alimentation (DGAL-Bureau de la Protection Animale), ACTA \& Direction de la Production et des Échanges (DPE)], ITAVI [Institut Technique de l'Aviculture] and the CIFOG [Comité Interprofessionel du Foie Gras].

\section{REFERENCES}

[1] Appleby M.C., Hugues B.O., Welfare of laying hens in cages and alternative systems: environmental, physical and behavioural aspects, World Poultry Sci. J. 47 (1991) 109 127. 
[2] Comité permanent de la convention européenne sur la protection des animaux dans les élevages, Recommandation concernant le canard de barbarie (Cairina moschata) et les hybrides de canard de barbarie et de canards domestiques (Anas platyrhynchos), T-AP 95 (20), 1999, 16 p.

[3] Dantzer R., Mormède P., Le stress en élevage intensif, Masson, Paris, 117 p.

[4] Dallman M.F., Stress Update, Adaptation of the hypothalamo-pituitary-adrenal axis to chronic stress, Trends Endocrin. Met. 4 (1993) 62-69.

[5] Duncan I.J.H., Wood-Gush D.G.M., Analysis of displacement preening in the domestic fowl, Anim. Behav. 20 (1972) 68-71.

[6] Duncan I.J.H., Wood-Gush D.G.M., Thwarting of the feeding behaviour in the domestic fowl, Anim. Behav. 20 (1972) 444-451.

[7] Etches R.J., Radioimmunoassay for corticosterone and its application to the measurement of stress in poultry, Steroids 28 (1976) 763 773.

[8] Faure J.M., Besoin en espace chez la poule, in: Picard M., Porter R.H., Signoret J.P (Eds.), Comportement et bien-être animal, INRA, Paris, 1994, pp. 161-167.

[9] Faure J.M., Guémené D., Guy G., Is there avoidance of the force feeding procedure in ducks and geese? Anim. Res. 50 (2001) 157164.

[10] Fraser A.F., Broom D.M., Farm animal behaviour and welfare, Ballière, Tindall, London, 1990, 437 p.

[11] Grandin T., Stress et manipulation des animaux, Rec. Méd. Vét. 164 (1988) 813-821.

[12] Guémené D., Guy G., Sansom M., Gouraud P., Garreau-Mills M., Faure J.M., Réponses physiologique et comportementale de l'oie à l'acte de gavage, $3^{\text {es }}$ Journées de la Recherche sur les Palmipèdes à Foie Gras, Bordeaux, France, 1998, pp. 69-73.

[13] Guémené D., Guy G., Noirault J., GarreauMills M., Gouraud P., Faure J.M., Forcefeeding procedure and physiological indicators of stress in male mule ducks, Brit. Poultry Sci. 42 (2001) 650-657.

[14] Guémené D., LeBihan-Duval E., Berri C., Baéza E., Garreau-Mills M., Responsiveness of the adrenocorticotrope axis in male turkeys of different genotypes, 6th Eur. Symp. on Poultry Welfare, Grp 9, WPSA, Zollikofen (Ch), 2001, pp. 312-313.

[15] Harbuz M.S., Lightman S.L., Stress and the hypothalamo-pituitary-adrenal axis: acute, chronic and immunological activation, J. Endocrinol. 134 (1992) 327-339.

[16] Janssens C.J.J.G., Helmond F.A., Wiegant V.M., Increased cortisol response to exogenous adrenocorticotropic hormone in chronically stressed pigs: influence of housing conditions, J. Anim. Sci. 72 (1994) 1771-1777.

[17] Jones B.R., Faure J.M., The effects of regular handling on fear responses in the domestic chick, Behav. Process. 6 (1981) 135-143.

[18] Keeling L.J., Gonyou H.W., Social behaviour in farm animals, CABI Publishing, Wallingford (UK), 2001, 406 p.

[19] Kettlewell P.J., Mitchell M.A., Catching, handling and loading of poultry for road transportation, World Poultry Sci. J. 50 (1994) 54-56.

[20] Koelkebeck K.W., Cain J.R., Amoss M.S., Use of adrenocorticotropin challenges to indicate chronic stress responses of laying hens in several housing alternatives, Domest. Anim. Endocrin. 3 (1986) 301-305.

[21] Landsberg J.-W., Weiss J., Stress and increase of the corticosterone level prevent imprinting in ducklings, Behaviour 57 (1976) 173-189.

[22] Le Maho Y., Karmann H., Briot D., Handrich Y., Robin J.P., Mioskowski E., Cherel Y., Farni J., Stress in birds due to routine handling and a technique to avoid it, Am. J. Physiol. 263 (1992) R775-R781.

[23] Mason G.J., Stereotypies: a critical review, Anim. Behav. 41 (1991) 1015-1037.

[24] Mitchell M.A., Maxwell M.H., Kettlewell P.J., Indicators of physiological stress in broiler chickens during road transportation, Anim. Welfare 1 (1992) 91-103.

[25] Mormède P., Les réponses neuroendocriniennes de stress, Rec. Méd. Vét. 164 (1988) 723-741.

[26] Nicol C.J., A study of the behavioural needs of battery housed hen, Ph.D. Thesis, Oxford University, 1986, 445 p. 
[27] Noirault J., Guémené D., Guy G., Faure J.M., Corticosterone plasma levels in male mule ducks: Effects of sampling sites, repeated samplings and ACTH injections, Brit. Poultry Sci. 40 (1999) 304-308.

[28] Rémignon H., Mills A.D., Guémené D., Desrosiers V., Garreau-Mills M., Marché M., Marché G., Meat Quality Traits and Muscle Parameters in High or Low Fear Lines of Japanese Quails (Coturnix japonica) Subjected to Acute Stress, Brit. Poultry Sci. 39 (1998) 372-378.

[29] Scientific Committee on Animal Health and Animal Welfare, Welfare aspects of the production of foie gras in ducks and geese, CEC, DGXXIV/B3/AW/R06, 1998, 94 p.
[30] Thorn G.W., Jenkins D., Laidlaw J.C., Goetz F.C., Dingman J.F., Arons W.L., Streeten D.H.P., MacRacken B.H., Medical progress: pharmacologic aspects of adrenocortical steroids and ACTH in man, New Engl. J. Med. 248 (1953) 232-248.

[31] Vuillaume A., Tournut J., Une nouvelle technique de prélèvement de sang chez les palmipèdes et les autres volailles, Group. Tech. Vét. 82 (4) AV-013 (1982) 83-87.

[32] Wiepkema P.R., On the significance of ethological criteria for the assessment of animal welfare, in: Smidt D. (Ed.), Indicators relevant to farm animal welfare, Martinus Nijhoff, The Hague (NL), 1983, pp. 71-79. 